methodological advice and supervision, and Julie Glanville helped with the design and implementation of search strategies. $\mathrm{JG}$ acts as guarantor for the paper.

Funding: English Department of Health as part of a larger programme of schizophrenia management guidelines to be undertaken by the National Institute of Clinical Excellence.

Competing interests: JG, as director of the Centre for Evidence Based Mental Health, has run workshops around the United Kingdom, organised independently, but often sponsored by pharmaceutical companies. The centre has therefore indirectly received fees and expenses from several of the companies who manufacture antipsychotic drugs. NF has received funds for research, fees, and expenses from several pharmaceutical companies who manufacture antipsychotic drugs and from the Department of Health in England. PH has received support from pharmaceutical companies to attend conferences. He has also received fees for educational lectures to psychiatrists on the psychopharmcology of schizophrenia and on the work described in this paper. $\mathrm{PB}$ has received fees for presentations at meetings sponsored by various pharmaceutical companies who manufacture typical and atypical antipsychotics. In addition he is one of the lead investigators of the European schizophrenia cohort funded by Lundbeck.

1 Kane JM, McGlashan TH. Treatment of schizophrenia. Lancet 1995; 346:820-5.

2 Bollini P, Pampallona S, Orza MJ, Adams ME, Chalmers TC. Antipsychotic drugs: is more worse? A meta-analysis of the published randomized control trials. Psychol Med 1994;24:307-16.

3 American Psychiatric Association. Practice guideline for the treatment of patients with schizophrenia. Washington, DC: APA, 1997.

4 Lehman AF, Steinwachs DM. Patterns of usual care for schizophrenia: initial results from the schizophrenia patient outcomes research team (PORT) client survey. Schizophr Bull 1998;24:11-20.

5 Wahlbeck K, Cheine M, Essali MA. Clozapine versus typical neuroleptic medication for schizophrenia In: Cochrane Collaboration. Cochrane Library. Issue 3. Oxford: Update Software, 1999

6 Duggan L, Fenton M, Dardennes RM, El-Dosoky A, Indran S. Olanzapine for schizophrenia In: Cochrane Collaboration. Cochrane Library. Issue 3. Oxford: Update Software, 1999.
7 Leucht S, Pitschel-Walz G, Abraham D and Kissling W. Efficacy and extrapyramidal side-effects of the new antipsychotics olanzapine, quetiapine, risperidone, and sertindole compared to conventional antipsychotics and placebo. A meta-analysis of randomized controlled trials. Schizophr Res 1999;35:51-68.

8 Srisurapanont M, Disayavanish C, Taimkaew K. Quetiapine for schizophrenia. In: Cochrane Collaboration. Cochrane Library. Issue 3. Oxford: Update Software, 1999.

9 Song F. Risperidone in the treatment of schizophrenia: a meta-analysis. J Psychopharmacol 1997;11:65-71.

10 Kennedy E, Song F, Hunter R, Clark A, Gilbody S. Risperidone versus typical antipsychotic medication for schizophrenia. In: Cochrane Collaboration. Cochrane Library. Issue 3. Oxford: Update Software, 1999.

11 Schulz KF, Chalmers I, Hayes RJ, Altman D. Empirical evidence of bias: dimensions of methodological quality associated with estimates of treatment effects in controlled trials. JAMA 1995;273:408-12.

12 Eccles M, Freemantle N, Mason JM. Methods of developing guidelines for efficient drug use in primary care: North of England evidence-based guidelines development project. BMJ 1998;316:1232-5.

13 Overall JE, Gorham DR The brief psychiatric rating scale. Psychological Reports 1962;10:799-812.

14 Kay SR, Fiszbein S, Opler LA. The positive and negative syndrome scale for schizophrenia. Schizophrenia Bull 1987;13:261-76.

15 Hedges LV, Olkin I. Statistical methods for meta-analysis. London: Academic Press, 1985.

16 Smith TC, Spiegelhalter DJ, Thomas A. Bayesian approaches to randomeffects meta-analysis: a comparative study. Stat Med 1995;14:2685-99.

17 DerSimonian R, Laird N. Meta-analysis in clinical trials. Control Clin Trials 1986;7:177-88.

18 Sutton AJ, Jones DR, Abrams K, Sheldon TA, Song F. Systematic reviews of randomised trials. In: Black N, Brazier J, Fitzpatrick R, Reeves B, eds. Health Services Research Methods. London: BMJ, 1998.

19 Allison DB, Mentore JL, Heo M, Chandler LP, Cappelleri JC, Infante MC, et al. Antipsychotic-induced weight gain: a comprehensive research synthesis. Am J Psychiatry 1999;156:1686-96.

20 Beasley CM, Dellva MA, Tamura RN, Morgenstern H, Glazer WM, Ferguson K, et al. Randomised double-blind comparison of the incidence of tardive dyskinesia in patients with schizophrenia during long-term treatment with olanzapine or haloperidol. Br J Psychiatry 1999;74:23-30.

21 Beasley CM. Olanzapine and tardive dyskinesia Br J Psychiatry 1999; 175:392.

(Accepted 3 October 2000)

\title{
Collusion in doctor-patient communication about imminent death: an ethnographic study
}

\author{
Anne-Mei The, Tony Hak, Gerard Koëter, Gerrit van der Wal
}

\section{See also Education and debate $\mathrm{p} 1400$ \\ Institute for Research in Extramural \\ Medicine/Department of Social Medicine, \\ Vrije Universiteit, Van der Boechorststraat 7, 1081 BT Amsterdam, \\ Netherlands \\ Anne-Mei The researcher \\ Tony Hak researcher \\ Gerrit van der Wal \\ professor}

continued over

BMJ 2000;321:1376-8

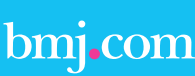

An additional box covering atypical cases can be found on the BMJ's website

\begin{abstract}
Objective To discover and explore the factors that result in "false optimism about recovery" observed in patients with small cell lung cancer.

Design A qualitative observational (ethnographic) study in two stages over four years.

Setting Lung diseases ward and outpatient clinic in university hospital in the Netherlands.

Participants 35 patients with small cell lung cancer. Results "False optimism about recovery" usually developed during the (first) course of chemotherapy and was most prevalent when the cancer could no longer be seen in the $x$ ray pictures. This optimism tended to vanish when the tumour recurred, but it could develop again, though to a lesser extent, during further courses of chemotherapy. Patients gradually found out the facts about their poor prognosis, partly because of physical deterioration and partly through contact with fellow patients who were in a more advanced stage of the illness and were dying. "False optimism about recovery" was the result an association between doctors' activism and patients' adherence to the treatment calendar and to the "recovery plot," which allowed them not to acknowledge explicitly what they should and could
\end{abstract}

know. The doctor did and did not want to pronounce a "death sentence" and the patient did and did not want to hear it.

Conclusion Solutions to the problem of collusion between doctor and patient require an active, patient oriented approach from the doctor. Perhaps solutions have to be found outside the doctor-patient relationship itself-for example, by involving "treatment brokers."

\section{Introduction}

Almost all patients with cancer want to know their diagnosis and most patients also want to be informed about the chance that they will be cured. ${ }^{1}$ This does not imply that these patients want to hear the really bad news about their condition. Many patients, when they fear that their prognosis is rather poor, do not ask for precise information and do not hear it if it is provided by the doctor. ${ }^{23}$ Our study started from the observation that, after their first course of chemotherapy virtually all patients with small cell lung cancer in a university hospital programme showed a "false optimism" about their recovery, in the sense that the patients' interpretations of their prognosis were 
considerably more optimistic than those of their doctors. It was not unusual for a patient to tell relatives and friends that the doctor had informed them that they were cured, when actually the cancer was not cured and the life expectancy of these patients was a maximum of two years.

We explored the reasons why virtually all these patients showed this false optimism. This topic is important because patients' ideas about their prognosis affect the choices they make regarding their treatment and end of life care. ${ }^{45}$ Initially we assumed that features of the communication between doctors (and nurses) and patients had caused this conflict between actual prognosis and what these patients seemed to believe. We examined which aspects of communication between doctors (and nurses) and patients contribute to the fact that patients do not know their poor prognosis. We studied in actual practice what information was given and what information was received and the effects on decision making about treatment and end of life care. ${ }^{6}$

\section{Methods}

The researcher (AT) initially carried out a study on the role of nurses in decisions concerning euthanasia on a ward for lung disease. ${ }^{7}$ Only the final phase of euthanasia could be observed, however, because the preparatory process had usually taken place in the outpatient clinic. To determine the moment when patients begin to talk about euthanasia and to investigate comprehensively the subsequent process we also had to make observations in the outpatient clinic During observations in the clinic it became apparent that patients there rarely dealt with their approaching death. In the waiting room, terminal patients with a maximum life expectancy of a few months said that the doctor had told them that they were cured. They were making plans for the future. In this way, by spending much time observing at the clinic and by focusing on the context of euthanasia, AT discovered the widespread occurrence, familiar to doctors and nurses, of false optimism about recovery. She also discovered that those concerned in the treatment of these patients in daily medical practice considered this false optimism to be a more important problem than euthanasia.

We designed a qualitative observational (ethnographic) study to discover and explore factors in the communication between patients and staff (doctors and nurses) that contribute to false optimism. ${ }^{8}{ }^{9}$ Data were collected through (full time) observation of patients in the lung diseases ward and clinic of a university hospital. After obtaining consent from patients, AT attended their outpatient clinic consultations, had informal conversations with patients and relatives in the clinic waiting room, accompanied them to $x$ ray and other hospital services, and also conducted more formal interviews with patients and staff. On many occasions patients were visited at home, particularly in the terminal phase of their illness when they had stopped attending the outpatient clinic. Funerals were attended and a small number of bereaved spouses interviewed.

In a first stage (1992-4) the researcher (AT) observed a group of 17 patients from initial diagnosis to their death. The size of the sample was based on AT's experience that it was not possible to keep intensive contact with more than about 15 patients and their families. After an initial analysis of the data collected in this first stage, in a second stage (1995-7) a group of 18 patients was observed from initial diagnosis to their death. Data from this second group of patients confirmed and specified findings from the first group.

From the start of both stages of data collection all new patients with a diagnosis of small cell lung cancer were asked to participate and to give their informed consent. The procedure was approved by the ethics committee. Only two eligible patients were not approached because they avoided any contact with the researcher (AT) from the outset. All approached patients gave their consent to be observed and interviewed and agreed to publication of anonymised extracts of observations and conversations in which they participated. Selection bias cannot be excluded but is unlikely. Participants' ages ranged from 45 to 70 years, and most (28) were men. Most of them were or had been heavy smokers, had attained a relatively low level of education, and had been employed in heavy physical work. All patients had received a first course of chemotherapy. Most of them received further courses after recurrence of the tumour. Radiotherapy was given only as a second or third line treatment in 13 cases, sometimes in combination with chemotherapy.

The analysis and results reported are based on four types of data. Firstly, the researcher (AT) made

\section{Box 1: Bad news consultation}

$\mathrm{Mr} \mathrm{G}$ and his wife come to see the consultant for the results.

"We talked on Monday after the bronchoscopy," says the consultant, "and I told you then that I was almost certain that there is a tumour in your lungs. That's how it looked. And, unfortunately, I must tell you that the lab tests have shown that it is cancer."

The consultant pauses, with a serious expression on his face.

Mr G closes his eyes. "How long have I got, doctor?"

"The type of lung cancer you have is very aggressive. It grows very fast. On the other hand-and that's an advantage if I may say so-this type of cancer is very sensitive to chemotherapy. It can certainly be treated. We can offer you treatment with chemotherapy, and I would definitely advise you to accept it. If we don't do anything, without treatment it could soon be over. In two or three months it could be the end. With therapy you must think in terms of years. It's difficult to say at this moment how long. It depends on so many things, for instance, how you respond to the therapy. We must wait and see how it develops before I can say anything definite."

After a short pause, the consultant continues, "At this moment we don't know whether it has spread. That must be investigated. But I can tell you that malignant cells have been found in the lymph glands. However, whether it has spread or not makes no difference to treatment. The advantage of chemotherapy is that it goes through the whole body."

"I want to try everything," interrupts Mr G, "Everything. I cannot leave her behind." He looks at his wife.

"We'll fight it together," says the consultant encouragingly, "However, I must tell you a few things about the treatment. Chemotherapy has side effects. Your hair will fall out. You might feel sick. But we can give you something for that. The therapy also affects your blood, and before we can give you any new treatment your blood must be healthy again. Treatment will be given in five sessions. Each time you will have chemotherapy."

"When can I begin, doctor?" interrupts Mr G, "Today?"

"You want to undergo therapy?" asks the consultant.

"Have I got a choice, doctor?"

The consultant shakes his head slowly.

"I've got my back to the wall," says Mr G.

"I'll try to arrange that you can start tomorrow. With this kind of tumour we cannot afford to lose time." 


\section{Box 2: The doctor's role in collusion}

The consultant sighs with relief when $\mathrm{Mr} \mathrm{H}$ has left the consultation room. "This is one of the most difficult things in my work. Just before the therapy I told him that his life expectancy was short and that this was the last thing I could do. He and his wife were crying all the time. Because they were very upset, I could not continue my explanation. That's why I wanted to talk to them again today. You saw what happened. They asked me again whether other therapies are available. Must I ruin their life by being honest? By telling things again that I have already told them? Or just leave it? That's a huge problem. I tell them once or twice what the situation is. If people want to know more, they must ask for it. I leave it to them."

"Do you find it difficult to break bad news?" the researcher asks.

"I think people must know what their situation is, but I find it difficult. What are the effects of what I say? That's my problem.'

comprehensive detailed field notes of her observations of the behaviour of patients and staff, within and outside consultations, and of her informal conversations with them. Secondly, formal interviews with patients and staff were tape recorded and transcribed. Thirdly, the researcher had access to the medical and nursing records of the patients who had given consent. Fourthly, the researcher also kept an ongoing diary in which she reported her own behaviour and feelings. These data were analysed per patient, resulting in 35 case studies. Each case analysis was aimed at a "thick description"10 and explanation of the information seeking and information avoiding strategies of that particular patient and of the changes in these strategies over time from diagnosis to the terminal phase of the illness. After the individual case studies were completed, similarities and differences between cases were analysed.

Analysis of six "atypical" cases was important to achieve a more comprehensive understanding of the information seeking and information avoiding strategies of most patients. Of these six, three refused treatment and three who received treatment did not show "false optimism" (details of these patients can be found on the BMJ's website). Two of the three patients who refused treatment were familiar with the plight of patients with incurable cancer, and the third had experienced so many other diseases and treatments that she did not want to participate in any again. The absence of "false optimism" in three patients who did receive treatment was related to their own or their children's relatively high educational level.

\section{Results}

\section{A common trajectory}

A common illness trajectory was found in 29 (out of 35) patients. This consisted of five stages: an "existential crisis" at diagnosis; a "focus on therapy" during the first treatment period; "relative peace of mind" during the period when the cancer was not visible in $x$ ray pictures; another "existential crisis" at the diagnosis of recurrence of the cancer; and the final crisis on receiving the news that no further treatment was available or feasible.

It seemed that the observed false optimism about recovery was not present to the same extent in all five stages. After patients were informed that they had cancer, there was immense despair resulting in an "existential crisis." Optimism usually developed during the (first) treatment period and was most prevalent in the third stage, when the cancer was not visible in $x$ ray pictures and the patient felt "cured." Optimism tended to vanish in the fourth stage, when the tumour recurred, but could develop again, though to a lesser extent, during further courses of chemotherapy. Gradually patients would find out the facts about their prognosis, partly because of physical deterioration and partly through contact with fellow patients who were in a more advanced stage of the illness and were dying.

\section{Concealment of prognosis}

In the consultation in which doctors informed patients that they had cancer, it was usually also mentioned that there was no cure. Details of the likely progress of the disease and about prognosis were rarely given. Patients were told that "it is extremely difficult to give any indication of the general prognosis because each patient is unique." In most cases this statement was followed immediately with an offer of chemotherapy. Uniqueness of individual patients was emphasised again with statements such as "We never know how an individual patient will respond to this therapy." Doctors said that they could provide more information (about prognosis) after the results of chemotherapy were available.

In actual practice, however, when "clean" $x$ ray pictures suggested that chemotherapy had been "successful," patients did not request further information on prognosis, believing that they were "cured." Later, when the inevitable relapse occurred, doctors told the patient that each relapse made treatment more difficult and the prognosis worse. Doctors would state again that an individual prognosis would depend on the results of future treatment and tests. The doctor gave information about the expected course of the illness only when he or she had a clinical reason (after diagnosis and with each tumour relapse) and did not explicitly formulate the prognosis until the patient was no longer considered "treatable" and was referred back to the general practitioner.

\section{Emphasis on treatment}

As indicated above, a characteristic feature of the consultation in which patients were told that they had cancer was a rapid transition from the provision of bad news to a discussion about what can be done about it (see box 2). By far the most time and energy was spent on "treatment" options. It is, however, important to note not only that the doctor instigated this but also that the patient eagerly complied and was keen to discuss the treatment options. When the patient was told that the cancer had returned, he immediately interrupted: "What can you do about it, doctor?" Throughout the treatment and remission period (second and third stages) discussions during consultations were almost entirely restricted to issues such as the planning of chemotherapy sessions, side effects, and test results. Both parties colluded in focusing on the "treatment calendar" and, at the same time, in ignoring the long term (prognosis and the likely shape of the illness trajectory). Although doctors and nurses openly discussed patients' (invariably poor) prognosis with each other-for example, at staff meetings-it was generally understood that this knowledge was not public and must not be conveyed to patients by nurses. In contrast, nurses could discuss arrangements for treatment and test results with patients at all times. 
Doctors thought it was their duty to mention the expected course of the disease when there was a medical occasion and if the patient asked for it, which rarely happened. The patients' not asking was interpreted by doctors as "not wanting to know." For the doctors, it was difficult to find a balance between what to say and what not to say. The emotions of the doctor played an important part (see box 2).

When patients persisted during their illness trajectory in "not wanting to know" doctors felt uncomfortable and showed a more active behaviour in trying to force a breakthrough in the awareness of the patient on the approaching death. But often patients made it clear that they didn't want to know the medical truth (see box 3). So we discovered that the false optimism about recovery was not only the result of the reluctance of doctors to give clear information about the prognosis but also of the part that patients played themselves. Patients had more influence on what was and was not said in the consultation than might be expected.

\section{Box 3: The patient's role in collusion}

Mr J lies in his hospital bed when the consultant sees him on his ward round, accompanied by a nurse and by the researcher.

"How are you today?" the doctor asks.

"I’m fine, doctor," says Mr J smiling. "We are planning a vacation with the whole family for the summer."

"That's very nice." The consultant waits for a moment. "I don't know how to put it..."

"We would like to go abroad," says Mr J cheerfully. "Mr J, I really think we have to talk. I have told you that the tumour has not responded to the chemotherapy and there are no other treatments. Actually, the tumour is growing. We could try radiation therapy but the chance..."

"Please doctor, will you stop it? When I fell ill, they told me this. When the cancer returned, they told me again. This week you told me, so this is the fourth time. Doctor, let's try the radiation therapy and leave me now."

\section{Ambiguities}

Words used by the doctors were often ambiguous. For example, the word "treatment" had a much more positive meaning for the patient than it had for the doctor. If the doctor stated that "this tumour can be treated" (meaning that there are treatments that prolong life), the patient heard that "something can be done about it"-in other words that he or she "can be cured." Apart from such unintentional ambiguity there was also intended ambiguity aimed at an incorrect overoptimistic interpretation by the patient of the results of chemotherapy. Examples are "the therapy has had the optimal effect," "the $x$ ray pictures show no abnormalities any more," and "your lungs are clear" (see box 4).

There were also forms of non-verbal ambiguity resulting from the mere fact that things were done. Patients just could not comprehend that the efforts and expense involved in the intensive treatment they got could be "useless" and hence did not (usually) result in being cured. Even if doctors explicitly stated that the treatment was palliative and merely life prolonging, the curative aura surrounding it gave another impression.

\section{Box 4: Good news consultation}

$\mathrm{Mr} \mathrm{K}$ and his wife look nervously at the consultant who is studying the new $x$ ray pictures, comparing them with previous ones.

"Marvellous," says the consultant, turning towards Mr and Mrs K, "Complete remission! Look, I'll show you. This is where the abnormality was." He points to a white spot in an old picture and moves on to another one. "And that's how it looked halfway through treatment. Half of the tumour had disappeared by then, and now there's nothing to be seen. Your lungs are clear." He looks cheerfully at Mr K, who gets up and bends over to look at the pictures himself.

"Nothing more to be seen," says Mr K, and to his wife, "Can you see that, dear?"

She nods happily.

"So it's looking good?" he asks.

"Very good," says the consultant, "Mr K, if I didn't know you, I wouldn't know where the abnormality had been. There is nothing to be seen in the last picture. Of course, there could always be a little cell left somewhere that we cannot see in the picture. That's always possible. Only time will tell."

\section{Knowing and not knowing}

Initially patients and relatives colluded with doctors in maintaining a "recovery plot": yesterday the patient was healthy, today he is ill, but tomorrow he will be better again, thanks to the efforts of the doctor and the patient, with support of carers.

Although all parties individually would have occasional doubts about the validity of this plot, they would not acknowledge this publicly so as not to be seen as undermining the others' trust in future recovery. This public adherence to the recovery plot, however, could not be maintained to the end of the illness trajectory. When patients experienced a relapse or when patients and their relatives observed how the condition of fellow patients deteriorated, doubts could be discussed. But even then, patients and relatives would do their best to adhere to the recovery story to spare each other anguish (see box 5).

In the final stages of the illness trajectory, adherence to the recovery story often resulted in a situation in which the patient was aware of the poor prognosis but did not explicitly acknowledge this. Depending on context, this awareness could seem to be present at one moment but virtually absent at another. These patients seemed to be involved in an ambiguous process of knowing and not knowing at the same time. The result was that it was possible that, in later stages of the illness trajectory, doctors and patients both knew that cure

\section{Box 5: Knowing and not knowing}

The researcher visits $\mathrm{Mr} \mathrm{L}$ at home. He is dying. Mrs $\mathrm{L}$ tells the researcher, "I've now accepted the fact that it's over. When the doctor told us two weeks ago that the tumour had become resistant to chemotherapy and that nothing could be done anymore, I suddenly realised how serious the situation is."

"Did you not know it before?" asks the researcher.

"How shall I say it. I knew and I didn't know. When he got ill, the doctor said that he had a tumour that had spread and that he never would get better. But then they started to talk about chemotherapy. I thought thanks goodness, something can be done about it. And I held on to that. It really didn't sink in. Later on I thought he's going to get better, otherwise they wouldn't go to all this trouble for him, would they? He got a lot better and everything was going fine and I was full of hope again. I thought it's all going to be all right. The day the doctor said that the tumour had come back for the third time and that there was no treatment option left, I suddenly realised the truth." 


\section{Box 6: Regret}

The researcher visits Mrs $\mathrm{L}$ at her home, some time after Mr L has died. They talk about the time when he was in treatment.

"What I find very difficult," says Mrs L, "is that my son cannot get over the fact that he went on holidays last Christmas, when he could have spent time with his father, and that the whole family could have been together. He could easily have taken holidays later on."

"Perhaps," she continues cautiously, "Perhaps the doctors should have told us more often and more clearly that it was the end. I didn't hear them say that My son would never have gone away last Christmas. Perhaps we would have realised sooner how serious the situation actually was."

was impossible and death imminent but even so told each other "recovery stories."

\section{Regret}

Recovery stories and the optimism sustained by them helped patients and relatives to endure the treatment phase, but, on the other hand, it was extremely painful when later it became clear that this optimism was based on illusions. Moreover, it made it more difficult to accept imminent death and it obstructed "saying farewell" in time and making necessary arrangements. Obviously, this false optimism also hindered patients in making sensible and well considered treatment decisions that are not based on fear. Retrospectively this was a reason for regret both for patients and relatives (see box 6).

\section{What is already known on this topic}

Many cancer patients, when they fear that their prognosis is poor, do not ask for precise information and do not hear it if it is provided by the doctor

In a cultural climate of openness and full disclosure it is not known how doctors and patients maintain a mutual pretence of "not knowing" a poor prognosis

\section{What this study adds}

This observational (ethnographic) study of patients with untreatable small cell lung cancer shows that doctors and patients collude in behaviour that fosters a false optimism about recovery

By focusing on the "treatment calendar" patients ignore the issue of prognosis

Patients' false optimism cannot be explained by doctors withholding information or a lack of communication skills, although both can play a part, because in such an explanation patients are one sidedly and erroneously portrayed as victims of doctors' behaviour

\section{Discussion}

Doctors seem to be actively involved in bringing stability to the uncertain life of patients by occupying them with all kinds of treatment activities (including chemotherapy) and planning (such as the arrangement of tests and check ups). This "medical activism," which might be related to a strong need for control in the Western world, helps both doctors and patients to divide the illness trajectory, which inevitably leads to death (within a maximum of two years), into much smaller, emotionally less charged, and more optimistic end points. By always looking forward to a next treatment session or appointment (short term) patients can avoid thinking about the longer term. Patients' optimism is a direct effect of this focus on the short term. The extreme form of this optimism in the third stage of the illness trajectory can be explained by the fact that the long term importance of the vanishing of the tumour from $x$ ray pictures-or rather the lack of it-is not recognised.

An important finding of our study is that the patients' false optimism about recovery is not only the result of the withholding of information from patients who are eager to know. On the contrary, patients seem to accept gratefully every opportunity offered by doctors to "forget" the future and to focus on the present, which is full of action (treatments, tests, etc). This recovery story is the dominant social discourse, and, in general, it is difficult for patients to deviate from it. ${ }^{12}$ This is particularly difficult when the vanishing of the tumour from the $x$ ray pictures unambiguously seems to confirm its validity.

\section{Applicability to other settings}

We consider our findings valid for the university clinic in which we conducted this study. We assume they are applicable to other Dutch clinics in which patients with small cell lung cancer are treated and, within these, to most patients who have not refused chemotherapy from the outset. With regard to the generalisability of our it must be remembered that small cell lung cancer is characterised by its extraordinary reactivity to first line chemotherapy. Although, generally, our findings agree with those of qualitative interview studies with cancer patients, ${ }^{23}$ applicability of our specific findings to other categories of patients and to other countries can be confirmed only by further ethnographic research. ${ }^{8}$ At present such research is regrettably scarce.

\section{Conclusions}

It seems that false optimism about recovery is the result of an association between doctors' activism and patients' adherence to the recovery plot, which allows them not to acknowledge explicitly what they both should know and can know. The doctor does and does not want to pronounce a "death sentence" and the patient does and does not want to hear it. Although patients (and their relatives) collude with their doctors in maintaining optimism, most of them regret this with hindsight. We conclude that it is not in the patients' interest to adhere to the "treatment calendar" in the early phases of the illness trajectory. Evidence for this is also comes from the cases of the three patients who did not have false optimism (see the extra box on the $B M J$ 's website). These patients were able to use the 
extra time provided by the effects of treatment in a conscious way to achieve their personal goals.

Breaking the cycle of collusion between doctor and patient is not primarily a question of whether the patient has to be informed at all, which usually is the case, but rather how doctors and patients deal with these facts in practice. Awareness cannot be forced on the patient, it can only be supported. This requires an active, patient orientated approach from the doctor. Perhaps solutions to the problem of false optimism about recovery and not knowing a poor prognosis have to be found outside the doctor-patient relationship itself. An example of such a solution would be the involvement of "treatment brokers," people who are trusted by the doctor and the patient and can help both parties in clarifying and communicating their (otherwise implicit) assumptions and expectations.

Contributors: A-MT was involved in the conception and the design of the study, collected all data, and contributed to the analysis and interpretation of the data. TH contributed to the analysis and interpretation of the data. GK was involved in the conception and the design of the study, supervised data collection, and contributed to the analysis of the data and the final version of the paper. GW contributed to the interpretation of the data and the drafting of the paper. A-MT and TH are guarantors.
Funding: Dutch Cancer Research Fund (Koningin Wilhelmina Fonds).

Competing interests: None declared.

1 Meredith C, Symonds P, Webster L, Lamont D, Pyper E, Gillis CR, et al Information needs of cancer patients in west Scotland: cross sectional survey of patients' views. BMJ 1996;313:724-6.

2 Costain Schou K, Hewison J. Experiencing cancer. Buckingham: Open University Press, 1999

3 Leydon G, Boulton B, Moynihan C, Jones A, Mossman J, Boudioni M, et al. Cancer patients' information needs and information seeking behaviour: in depth interview study. BMJ 2000;320:909-13

4 Weeks JC, Cook FE, O'Day SJ, Peterson LM, Wenger N, Reding D, et al. Relationship between cancer patients' predictions of prognosis and their treatment preferences. JAMA 1998;21:1709-14.

5 Christakis NA. Death foretold; prophecy and prognosis in medical care. Chicago: University of Chicago Press, 2000.

6 Smith TJ, Swisher K. Telling the truth about terminal cancer (editorial). JAMA 1998;21:1746-8.

7 The A-M. Nursing dilemmas in euthanasia and other end-of-life decisions. Houten: Bohn Stafleu Van Loghum, 1997 (in Dutch).

8 Mays N, Pope C. Qualitative research: observational methods in health care settings. BMJ 1995;311:182-4.

9 The A-M. Palliative care and communication. Houten: Bohn Stafleu Van Loghum, 1999 (in Dutch).

10 Geertz C. The interpretation of cultures. New York: Basic Books, 1973.

11 Nuland SW. How we die:reflections on life's final chapter. London: Chatto and Windus, 1994.

12 Frank AW. The wounded storyteller: body, illness and ethics. Chicago: University of Chicago Press, 1995.

(Accepted 18 September 2000)

\section{Using the modified Barthel index to estimate survival in cancer patients in hospice: observational study}

Mike Bennett, Nicola Ryall

Professionals in palliative care often base clinical decisions on estimated prognosis, but it has been shown that they are less accurate than the Karnofsky index at predicting prognosis in terminally ill patients. ${ }^{12}$ Because our clinical experience suggested that in patients in hospice the rate of change in physical functioning was a more useful indicator of survival than absolute measures, we investigated the use of rate of change of physical function in estimating survival of terminally ill patients with cancer by using the modified Barthel index. This comprises 10 activities of daily living, each with five levels of dependency; the maximum score is 100 points, representing independence in daily living. We thought it was a more sensitive index for measuring physical functioning in this patient group than the Karnofsky index. ${ }^{3}$

\section{Patients, methods, and results}

We studied two samples of patients with cancer from the same hospice to generate and test the model. We determined sample sizes empirically from patients admitted consecutively over two different periods of two months (January-February and March-April 1998), in whom the modified Barthel index was determined weekly from admission for the duration of inpatient stay. Barthel score at admission, mean weekly change in score during inpatient stay (defined as final score minus admission score divided by length of stay), and survival from date of admission were recorded.
The two populations were similar with respect to Barthel score at admission, length of stay, and survival (table). In sample 1, survival correlated with Barthel score at admission $(r=0.25, \mathrm{P}=0.014)$ but more closely with mean weekly change $\left(r_{\mathrm{s}}=-0.52, \mathrm{P}<0.001\right)$. To examine this relation further, three groups were pragmatically constructed from the first sample on the basis of mean weekly change in Barthel scores. These represented clinical patterns commonly seen in terminally ill patients: stable physical functioning (no loss of points), moderate deterioration (1-9 points lost per week), and marked deterioration (10 or more points lost per week).

This model was applied to sample 2 to assess its ability to estimate survival. Survival correlated with Barthel score at admission $\left(r_{s}=0.3, \mathrm{P}=0.002\right)$ but more closely with mean weekly change $\left(r_{s}=-0.52\right.$, $\mathrm{P}<0.001)$. Corresponding groups between samples had similar median survival, but the differences in survival between the three groups within each sample were significant (table).

\section{Comment}

In terminally ill patients in a hospice, rates of change were more important indicators of survival than absolute measures. Mean change in weekly Barthel scores was calculated to provide a crude clinical marker of changing physical function. Using mean change assumes that the modified Barthel index is an interval $\begin{array}{ll}\text { St Gemma's } & \text { Hospice, Leeds } \\ \text { LS17 6QD } & \text { Mike Bennett } \\ \text { consultant in } \\ \text { palliative medicine } \\ \text { Rheumatology and } \\ \text { Rehabilitation } \\ \text { Research Unit, } \\ \text { Leeds LS2 9NZ }\end{array}$

anj's website 